\title{
Analysis of Al in Zn Hot Dip Galvanizing Bath Sample by X-ray Fluorescence Spectrometry
}

\author{
Yoshiro MATSUMOTO \\ Iron and Steel Research Laboratories, Sumitomo Metal Industries, Ltd., Fuso-cho, Amagasaki, Hyogo-ken, 660 Japan.
}

(Received on April 8, 1991; accepted in final form on November 15, 1991)

In the production of $\mathrm{Zn}$ hot dip galvanized steel sheets, the concentration of $\mathrm{Al}$ in the galvanizing bath must be maintained within a limited range to ensure optimum performance. For this purpose, an accurate and rapid determination of $\mathrm{Al}$ by $\mathrm{X}$-ray fluorescence spectrometry was studied. The results were as follows:

(1) The AIK $\alpha$ line intensity increased with the lapse of time after sample preparation because of the enrichment of Al near the surface of the sample.

(2) An accurate and rapid analysis was performed by preparing a sample with an SiC abrasive paper of coarse grit size 40 and by starting the $X$-ray intensity measurement after a brief 3 min lapse of time following the sample preparation.

KEY WORDS: Al concentration; Zn hot dip galvanizing; $X$-ray fluorescence analysis; sample preparation.

\section{Introduction}

In the production of $\mathrm{Zn}$ hot dip galvanized steel sheets, the Al content in the galvanizing bath must be controlled to ensure the coating adhesion quality of the sheet. ${ }^{1)}$ The X-ray fluorescence spectrometric method is widely used for the analysis of $\mathrm{Al}$ in the bath. However, analytical precision and accuracy of this method have been poor because the measured $A l K \alpha$ line intensities increase with time owing to the Al enrichment in the near surface of the sample caused by oxidation. Little study of the analysis has been performed. The present paper describes the effects of grit size of abrasive paper for a surfaced disk sample and the starting time of $\mathrm{X}$-ray intensity measurement following surfacing of the sample on analytical precision and accuracy.

\section{Experimental}

$\mathrm{X}$-ray fluorescence intensity measurement was made with a sequential wavelength-dispersive type spectrometer (Rigaku, IKF-4). Measurements were made under the following conditions. AlK $\alpha$ line intensity: $\mathrm{Cr} \mathrm{X}$-ray tube, $40 \mathrm{kV}-60 \mathrm{~mA}$ tube voltage and current, and PET $(002)^{2)}$ (pentaerythritol, $\left.\mathrm{C}\left(\mathrm{CH}_{2} \mathrm{OH}\right)_{2}\right)$ analyzing crystal. $\mathrm{ZnK} \alpha$ line intensity: $\mathrm{Cr}$ X-ray tube, $25 \mathrm{kV}-2 \mathrm{~mA}$ tube voltage and current, and LiF (200) (lithium fluoride) analyzing crystal. The phenomenon of enrichment of $\mathrm{Al}$ in the near surface of the sample was confirmed by GDS (glow discharge spectrometry). GDS measurement: $\phi 6 \mathrm{~mm}$ electrode, $1000 \mathrm{~V}$ discharge voltage, $530 \mathrm{~Pa} \mathrm{Ar}$ pressure, and the AlI $396.15 \mathrm{~nm}$ and $\mathrm{ZnI} 334.50 \mathrm{~nm}$ analytical lines. Reference samples were prepared in a laboratory and the content of $\mathrm{Al}$ in the samples was determined by ICP (inductively coupled plasma spectrometry). $\mathrm{SiC}$ abrasive papers ${ }^{3-5)}$ of 40,320 and 600 grit sizes were used for sample polishing.

\section{Experimental Results and Discussions}

\subsection{Effect of Specimen Polishing on X-ray Fluorescence Intensity}

Variations in the $\mathrm{AlK} \alpha$ and $\mathrm{ZnK} \alpha$ line intensities were examined. After polishing, a sample was set in the sample chamber of the X-ray fluorescence spectrometer and the intensity was continuously measured under the following conditions; $1.3 \mathrm{~Pa}$ evacuation, $30 \mathrm{rpm}$ sample rotation, and $20 \mathrm{sec}$ rate meter time constant. The time taken to set a sample in the spectrometer and evacuate the sample chamber was $3 \mathrm{~min}$; for this reason, the $\mathrm{X}$-ray intensity measurement was begun at 3 min after sample polishing (Fig. 1). The measured intensities are normalized in such a way that the intensity at the starting point ( $3 \mathrm{~min}$ ) is the unit of each abrasive paper grit size. Preliminary experiments revealed that the intensity measured under atmospheric conditions (the sample chamber was intermittently evacuated at $1.3 \mathrm{~Pa}$ during the $\mathrm{AlK} \alpha$ line intensity measurement) did not differ from that under the evacuated condition (1.3 Pa). The $\mathrm{AlK} \alpha$ line intensities at $60 \mathrm{~min}$ lapse were $1.1,1.2$ and 1.3 times the intensities at $3 \mathrm{~min}$ for abrasive papers of 40,320 and 600 grit sizes, respectively. The increase in the $\mathrm{A} 1 \mathrm{~K} \alpha$ line intensity was small in the case of an abrasive paper of 40 grit size. Moreover, the $\mathrm{AlK} \alpha$ line intensities in the $120 \mathrm{~h}$ experiment varied as shown in Fig. 2. In this experiment, the sample was allowed to stand in contact with the atmosphere, and the AlK $\alpha$ line intensity measurement was carried out under a $1.3 \mathrm{~Pa}$ 


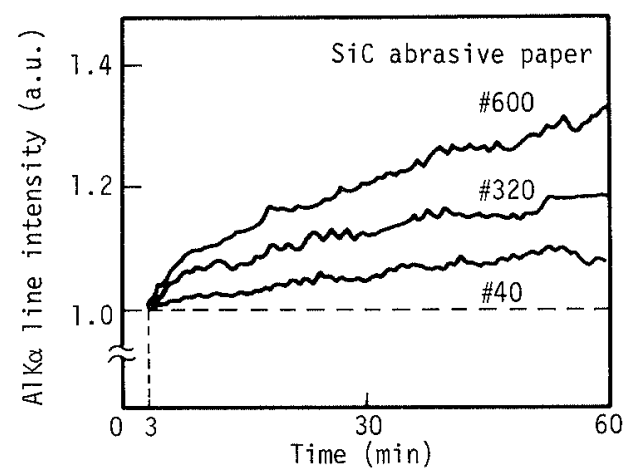

Fig. 1. Variation in the AlK $\alpha$ line intensity as a function of elapsed time after sample preparation with $\mathrm{SiC}$ abrasive papers of 40,320 and 600 grit size. The Al content in the $\mathrm{Zn}$ sample used for the experiment was $0.13 \%$.

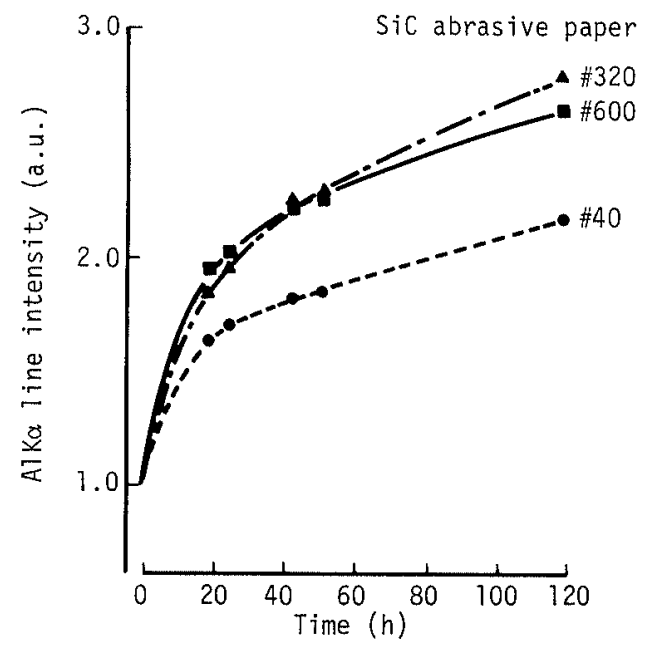

Fig. 2. Variation in the AlK $\alpha$ line intensity as a function of elapsed time after sample preparation. The observation period was $120 \mathrm{~h}$ (see Fig. 1).

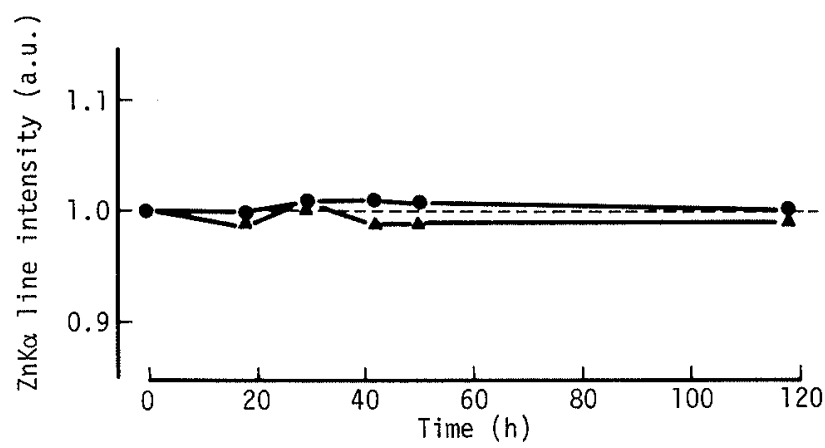

Fig. 3. Variation in the $\mathrm{ZnK} \alpha$ line intensity as a function of elapsed time after sample preparation. $\mathrm{SiC}$ abrasive papers: $\bullet, \# 40, \boldsymbol{\Lambda}, \# 600$.

evacuated condition. Duration of each measurement was $100 \mathrm{sec}$. Variations with time in the $\mathrm{ZnK} \alpha$ line intensity of a $\mathrm{Zn}$ sample and the $\mathrm{AlK} \alpha$ line intensity of a steel sample were compared. The $\mathrm{ZnK} \alpha$ line intensity-time curve for the $\mathrm{Zn}$ sample and the $\mathrm{AlK} \alpha$ line intensity-time curve obtained with JSS (Japanese Standard Sample) FXS353 $(\mathrm{Al}=0.18 \%)$ are shown in Figs. 3 and 4, respectively. Variations in the intensities were comparatively smaller than that of the $\mathrm{AlK} \alpha$ line

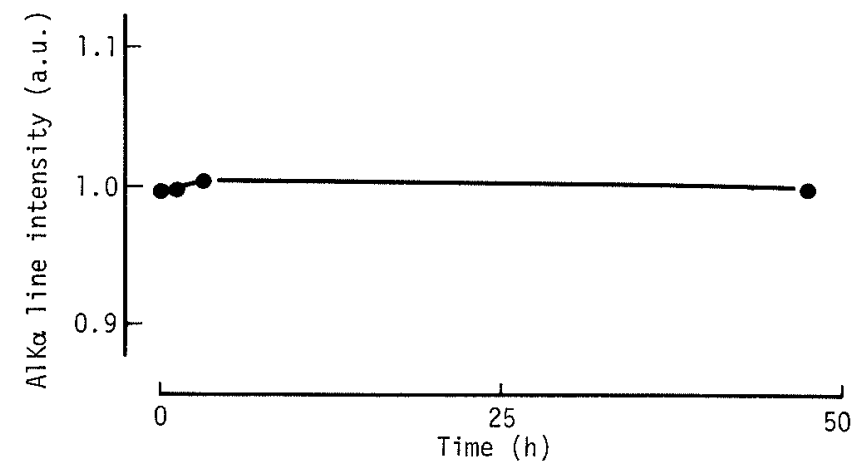

Fig. 4. Variation in the $A I K \alpha$ line intensity as a function of elapsed time after sample preparation for JSS standard sample FXS 353 (Fe-0.18\% Al). The sample was surfaced with an $\mathrm{SiC}$ abrasive paper of 40 grit size.

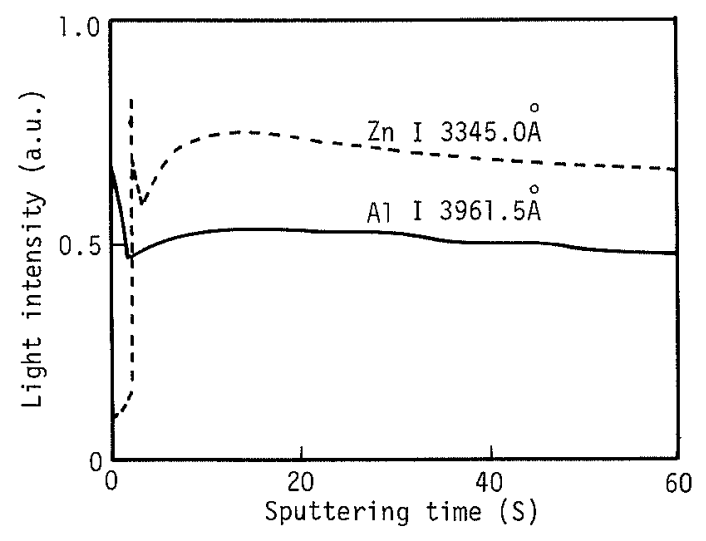

Fig. 5. Glow discharge spectrometric depth profile of a $\mathrm{Zn}$ sample containing $0.13 \% \mathrm{Al}$ measured at $16 \mathrm{~h}$ after sample preparation.

Sample preparation: SiC abrasive paper of 320 grit size; diameter of clectrode: $\phi 6 \mathrm{~mm}$; Ar gas pressure: $530 \mathrm{~Pa}$; discharge voltage: $1000 \mathrm{~V}$ const; analytical lines: AlI $396.15 \mathrm{~nm}$, and $\mathrm{ZnI} 334.50 \mathrm{~nm}$.

intensity of the $\mathrm{Zn}$ sample.

\subsection{Enrichment of $A l$ in the Near Surface of the Sample}

The phenomenon of the $\mathrm{Al}$ enrichment in the near surface of the polished sample was confirmed by GDS. GDS depth profiles of $\mathrm{Al}$ and $\mathrm{Zn}$ are shown in Fig. 5. The sample was surfaced with an $\mathrm{SiC}$ abrasive paper of 320 grit size and the measurement was made at $16 \mathrm{~h}$ after sample preparation (the sample was allowed to stand for a long period of $16 \mathrm{~h}$ in contact with the atmosphere to permit detection of the $\mathrm{Al}$ enrichment phenomenon). The $\mathrm{Al}$ and $\mathrm{Zn}$ line intensities were higher and weaker, respecrively, at the surface. From the GDS data, the enrichment of $\mathrm{Al}$ caused by oxidation is considered to take place in the near surface of the sample. ${ }^{6)}$

\subsection{Effect of Abrasive Paper Grit Size}

Variation in the AlK $\alpha$ line intensity with increasing elapsed time after sample preparation when the $\mathrm{X}$-ray beam was perpendicular or parallel ${ }^{3,7)}$ to the polishing striations is shown in Fig. 6. With an abrasive paper of 40 grit size the $A I K \alpha$ line intensity increased with time when the X-ray beam was parallel to the striations. 
(a) Cross section of sample surface \#40

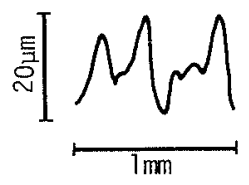

(b) Variation in $\mathrm{AlK} \alpha \mathrm{l}$ ine intensity

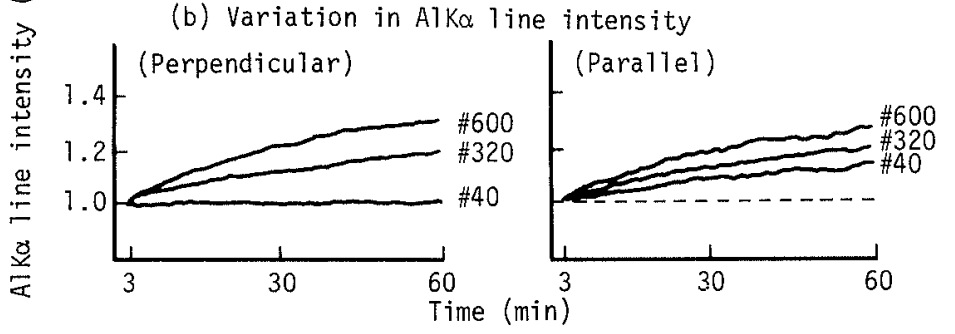

$\# 600$

Fig. 6.

Effect of abrasive paper grit size and the direction of $\mathrm{X}$ ray beam to sample surface striations on $\mathrm{AlK} \alpha$ line intensity-time curves.

Perpendicular: the polishing striations were perpendicular to X-ray beam.

Parallel: the polishing striations were parallel to $\mathrm{X}$-ray beam.

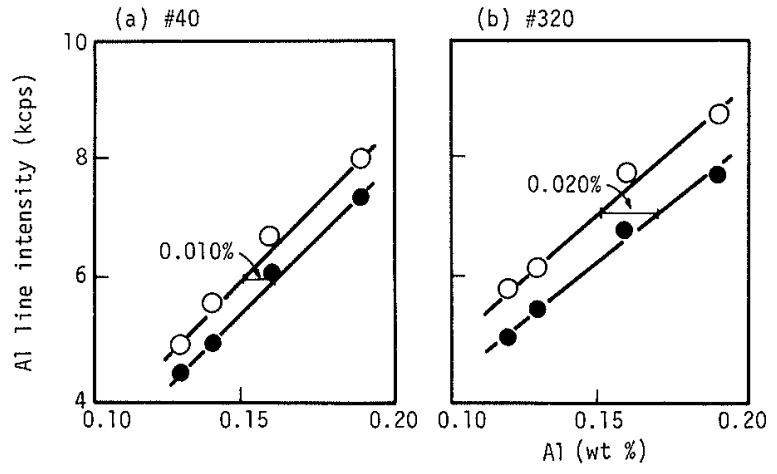

However, the increase in the intensity was weaker when the X-ray beam was perpendicular to the striations. The calculated (effective) thickness ${ }^{8)}$ at $99 \%$ of the infinite thickness intensity was $0.86 \mu \mathrm{m}$ in the case of $\operatorname{CrK} \alpha$ incident $\mathrm{X}$-ray and $60-35^{\circ}$ incident-takeoff angles. In the calculation the mass absorption coefficient of zinc used was $180 \mathrm{~cm}^{2} / \mathrm{g}^{9)}$ for the $\operatorname{CrK} \alpha$ line and that $4200 \mathrm{~cm}^{2} / \mathrm{g}^{9)}$ for $\mathrm{AlK} \alpha$ were used. Striation depths obtained from striation cross sections were $20 \mu \mathrm{m}$ for an abrasive paper of 40 grit size, $2 \mu \mathrm{m}$ for 320 , and $1 \mu \mathrm{m}$ for 600 . When the X-ray beam was parallel to the striations, the AlK $\alpha$ line X-ray was detected from a small part of the striation top. When the X-ray beam was parallel to the striations, the detected $\mathrm{A} 1 \mathrm{~K} \alpha$ line intensity increased with the lapse of time owing to the enrichment of $\mathrm{Al}$ which took place in the near surface of the sample. With the X-ray beam perpendicular to the striations, however, the $\mathrm{AlK} \alpha$ line intensity did not increase because no enriched $\mathrm{Al}$ was detected on the valley part (the shield effect). ${ }^{10)}$ As a result, the increase in the $\mathrm{AlK} \alpha$ line intensity was weaker for an abrasive paper of 40 grit size.

\subsection{Analytical Accuracy}

The relationships between the $\mathrm{AlK} \alpha$ line intensity and Al percentage are shown in Fig. 7. The analytical line for $60 \mathrm{~min}$ of elapsed time after sample preparation is at a higher intensity position than that for $3 \mathrm{~min}$. The sample of $0.15 \% \mathrm{Al}$ level at the time elapsed of $60 \mathrm{~min}$ after sample preparation is determined higher by 0.010 , 0.020 and $0.046 \%$ for abrasive papers of 40,320 and 600 grit sizes, respectively, reading from the analytical curve for the time elapsed of $3 \mathrm{~min}$. It is thus understood that analytical precision and accuracy became poor (c) $\# 600$

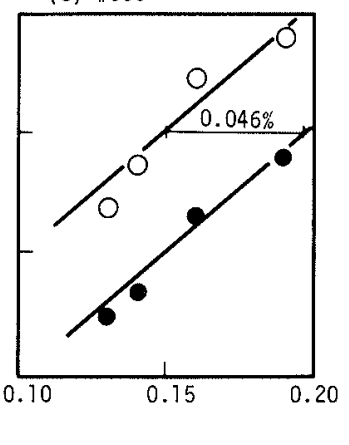

Fig. 7.

Analytical curves as a function of the elapsed time after surface preparation and $\mathrm{SiC}$ abrasive paper grit size.

$\mathrm{X}$-ray measurement starting time after sample preparation: $\bullet, 3 \mathrm{~min}, 0,60 \mathrm{~min}$.

Table 1. Analytical accuracy. $\left(\sigma_{d}\right.$, wt $\left.\%\right)$

\begin{tabular}{rccc}
$\begin{array}{r}\text { Time } \\
(\mathrm{min})\end{array}$ & $\# 40$ & $\begin{array}{c}\text { SiC abrasive paper } \\
\# 320\end{array}$ & $\# 600$ \\
\hline 3 & 0.002 & 0.003 & 0.004 \\
60 & 0.004 & 0.004 & 0.007 \\
\hline
\end{tabular}

Note: Time means the X-ray measurement starting time after sample preparation.

when X-ray intensity measurement was made without specifying the lapse of time elapsed after sample preparation.

The analytical accuracy was calculated by

$$
\sigma_{d}=\sqrt{\sum d^{2} /(n-1)}
$$

where, $d$ : (X-ray fluorescence analytical value) -(chemical analysis value)

$n$ : number of samples.

The results are shown in Table 1 . The analytical accuracies at $3 \mathrm{~min}$ after polishing were $0.002,0.003$ and $0.004 \%$ for abrasive papers of 40,320 , and 600 grit sizes, respectively. An excellent accuracy was obtained with an abrasive paper of 40 grit size. Accuracies at $60 \mathrm{~min}$ after sample polishing were $0.004,0.004$ and $0.007 \%$ for abrasive papers of 40,320 and 600 grit sizes, respectively, reading from the analytical curve $60 \mathrm{~min}$. These accuracies were poorer than those of $3 \mathrm{~min}$.

In the X-ray fluorescence analysis of light elements such as $\mathrm{Si}, \mathrm{Al}$ and $\mathrm{Mg}$ in metallic samples, fine polishing is recommended because a polishing striation more than a few $\mu \mathrm{m}$ deep makes accuracy poor. ${ }^{2,3,8,10)}$ In the 
$\mathrm{X}$-ray fluorescence analysis of $\mathrm{Al}$ in $\mathrm{Zn}$ studied in the present work, however, the enrichment of $\mathrm{Al}$ took place by oxidation. The $\mathrm{Al}$ content of bulk was different from that of the near surface of the sample. When a fine abrasive paper was used to polish the sample, the rate of increase of the AlK $\alpha$ line intensity was high. Thus, this intensity did not greatly change when an abrasive paper of 40 grit size was used and an excellent analytical accuracy was able to obtain.

\section{Conclusions}

The enrichment of $\mathrm{Al}$ in the near surface of a sample took place and the $\mathrm{AlK} \alpha$ line intensity increased with time elapsed after sample polishing. The rate of increase of the measured $\operatorname{AlK} \alpha$ line intensity depended on the roughness of the polishing. The $\mathrm{AlK} \alpha$ line intensities at $60 \mathrm{~min}$ after polishing were 1.1, 1.2 and 1.3 times those at $3 \mathrm{~min}$ for $\mathrm{SiC}$ abrasive papers of 40,320 and 600 grit sizes, respectively. It was therefore necessary to specify the elapsed time from sample polishing to the start of X-ray intensity measurement, for example $3 \mathrm{~min}$. Analytical accuracies of $3 \mathrm{~min}$ measurement were 0.002 ,
0.003 and $0.004 \%$ for abrasive papers of 40,320 and 600 grit sizes, respectively. Increase in the intensity rate was least and excellent accuracy was obtained with an abrasive paper of 40 grit size.

\section{REFERENCES}

1) M. Ohbu, K. Asakawa and K. Tano: Tetsu-to-Hagané, 60 (1974), 705.

2) H. K. Herglotz and L. S. Birks: X-ray Spectrometry, Marcel Dekker, New York, (1978), 10, 279, 282, 316.

3) R. Tertian and F. Classe: Principles of Quantitative X-ray Fluorescence Analysis, Heyden, London, (1982), 317.

4) Japanese Industrial Standard JIS R6252, (1976).

5) R. Jenkins, R. W. Gould and D. Gedcke: Quantitative X-ray Spectrometry, Marcel Dekker, New York, (1981), 371.

6) S. Maeda, T. Asai, K. Suzuki and M. Higuchi: Tetsu-to-Hagané, 64 (1978), A 139.

7) E. P. Bertin: Introduction to X-ray Spectrometric Analysis, Plenum, New York, (1978), 403.

8) E. P. Bertin: Principles and Practice of X-ray Spectrometric Analysis, Plenum, New York, (1970), 457.

9) L.S. Birks: Electron Probe Microanalysis, Interscience Publishers, New York, (1963), 201.

10) H. A. Liebhafsky, H. G. Pfeiffer, E. H. Winslow and P. D. Zemany: X-rays, Electrons, and Analytical Chemistry, WileyInterscience, New York, (1972), 442. 